\title{
Characterization and retrieval of snow and urban land cover parameters using hyperspectral imaging
}

\author{
S. K. Singh ${ }^{1, *}$, Gaurav Jain ${ }^{1}$, Asfa Siddiqui ${ }^{2}$, Smruti Naik ${ }^{1}$, B. P. Rathore ${ }^{1}$, \\ Vaibhav Garg', Snehmani ${ }^{3}$, Vinay Kumar ${ }^{2}$, I. M. Bahuguna ${ }^{1}$, S. A. Sharma ${ }^{1}$, \\ Chander Shekhar ${ }^{3}$, Praveen K. Thakur ${ }^{2}$, Kavach Mishra ${ }^{2}$, Pramod Kumar ${ }^{2}$, \\ T. H. Painter ${ }^{4}$ and J. Dozier 5 \\ ${ }^{1}$ Space Applications Centre, Indian Space Research Organisation (ISRO), Ahmedabad 380 015, India \\ ${ }^{2}$ Indian Institute of Remote Sensing, ISRO, Dehradun 248001 , India \\ ${ }^{3}$ Snow and Avalanche Study Establishment, Chandigarh 160 036, India \\ ${ }^{4}$ University of California, Los Angeles, CA, USA \\ ${ }^{5}$ University of California, Santa Barbara, CA, USA
}

Snow and urban land cover are important due to their role in hydrological management and utility, climate response, social aspects and economic viability, along with influencing the Earth's environment at local, regional and global scale. Hyperspectral data enable identification, characterization and retrieval of these land-cover features based on physical and chemical properties of compositional materials. AVIRISNG hyperspectral airborne data, with synchronous ground observations using field spectroradiometer and collateral instruments, were collected over two widely varied land-cover types, viz. a relatively homogenous area covered by snow in the extreme cold environment of the Himalaya (Bhaga sub-basin, Himachal Pradesh), and a completely heterogeneous urban area of a metropolitan city (Ahmedabad, Gujarat).

AVIRIS-NG airborne data were analysed to understand the effect of terrain parameters such as slope and aspect on snow reflectance. Snow grain index using visible and near-infrared (VNIR) bands and absorption peak in the near-infrared (NIR) were used to retrieve grain size in parts of the Himalayan region. A radiative transfer model was used to understand the grain size variability and its effect on absorption peak in NIR. Continuum removal was performed for snow spectral observations obtained from airborne, modelled and field platforms to estimate band depth at $1030 \mathrm{~nm}$. Grain size was observed to vary with altitude from 100 to $500 \mu \mathrm{m}$ using AVIRIS-NG image. In the urban area, the data also separated pervious and impervious surface cover using spectral unmixing technique, identified several urban features over multispectral data such as buildings with red tiled roofs, metallic surfaces and tarpaulin sheets using the material spectral profiles. Two single-frame superresolution methods namely sparse regression and natural prior (SRP), and gradient profile prior (GPP) were applied on AVIRIS-NG data for the mixed environment around Kankaria Lake in the city of Ahmedabad, which revealed that SRP method was better than GPP, and affirmed by eight indices. Preliminary analysis of AVIRIS-NG imaging over snow-covered areas and densely populated cities indicated utility of future spaceborne hyperspectral missions, particularly for hydrological and climatological applications in such diverse environments.
Keywords: AVIRIS-NG, hyperspectral imaging, snow reflectance, super-resolution method, terrain parameters, urban land cover.

\section{Introduction}

SNOW and urban land cover are interlinked by their role in the supply and demand of water to meet various needs, as well as in climate at varying scales. Snow, the solid phase of water, is an important component of the Earth

\footnotetext{
*For correspondence. (e-mail: sushil@sac.isro.gov.in)
}

system which occurs in high altitude mountainous and polar region, contributing in hydrological and climatological status at local, regional and global scale. Being a bright target in the optical region, snow reflects strongly in visible and near-infrared (VNIR) region and is a strong absorber in shortwave infra-red (SWIR) region, leading to operational snow cover monitoring studies using multispectral sensors from the space ${ }^{1-4}$. Snow reflectance is severely affected at different parts of the electromagnetic (EM) spectrum $(0.4-2.5 \mu \mathrm{m})$ due to impurities in snow, grain size variation, presence of liquid water content, solar zenith angle, ageing, cloud cover, etc. ${ }^{5-7}$. Presence of liquid water content between ice crystal leads snow to 
behave as optically larger grains ${ }^{8}$. Variation in snow grain affects reflectance in NIR region which has been used to retrieve grain size from hyperspectral observation $^{9-12}$. Dozier and Painter ${ }^{13}$ have provided a review on the retrieval of snow physical parameters from multispectral and hyperspectral data, emphasizing on the requirement and challenges to improve hydrological and climatological models. Hyperspectral radiometric observations in the Himalayan region have been used to examine the effect of amount and type of contamination, grain size, mixed snow pixel, liquid water content, ageing and viewing geometry on snow reflectance ${ }^{14-17}$. Negi and Kokhanovsky $^{18}$ used asymptotic radiative transfer approach to estimate grain size and albedo, where grain size retrieval works well for dry snow in the Upper Himalaya but fails in the lower and middle Himalaya due to low reflectivity in the NIR region. A statistical (Variogram) approach was used between snow reflectance $(1033 \mathrm{~nm}$ (a) band 89 in hyperion) and grain size to develop linear and exponential relationship with 0.86 correlation coefficient, and further implemented to retrieve grain size using Hyperion image over Heihe river basin in China ${ }^{19}$. Grain index (GI) was estimated using channels centred at 590 and $1050 \mathrm{~nm}$ to broadly classify snow grain size using ground-based spectroradiometer data in the Himalayan region ${ }^{16}$. AVIRIS airborne data have been used to retrieve three phases of water ${ }^{20}$, with MEMSCAG (multiple endmember snow-covered area and grain size) model to retrieve subpixel snow cover area and grain size over Mammoth mountains, CA, USA ${ }^{21}$, and imaging spectrometer-snow albedo and radiative forcing (IS-SnARF) suite to retrieve snow grain size, albedo and radiative forcing by impurities over Senator Beck Basin Study Area, USA ${ }^{22}$. Negi et al. ${ }^{23}$ have presented a review of hyperspectral applications, its limitations and future research issues focusing on Himalayan snow and glaciers.

Urban areas are characterized by high proportion of impervious land cover, and are known to be the primary cause of increased run-off volumes in the cities, resulting into frequent inundations, besides being a major contributor to non-point source pollution of water bodies ${ }^{24}$, prevalence of urban heat island effect in cities ${ }^{25}$, and associated health hazards. Remote sensing has been one of the primary sources of information on impervious surfaces ${ }^{24,26}$. Multispectral data from Landsat and SPOT satellite series have been widely used for characterizing urban areas, either using vegetation-impervious surface-soil (VIS) model $^{27-29}$, or by abundance of individual composition materials such as vegetation ${ }^{30}$ or impervious surface ${ }^{31}$. In urban areas, due to considerable variability in the size of objects, very high spatial resolution data are preferred for the estimation of impervious surfaces ${ }^{26,32}$. The utility of spectral measurements in the identification of urban materials has been explored with spectral library developed by field spectroscopy ${ }^{33-36}$. Herold et al. ${ }^{33}$ collected spectral profiles of over 4500 urban targets identifying
108 materials in urban areas using field spectroscopy, and determined nine bands, including four in VIS (420, 440, 570 and $640 \mathrm{~nm})$, three in NIR $(750,1105$ and $1315 \mathrm{~nm})$ and one in SWIR $(1990 \mathrm{~nm})$, that resulted into best average separation of these materials. Weng et al. $^{37}$ demonstrated application of EO-1 Hyperion imagery in the extraction of impervious surfaces such as roads, building roofs, sidewalk and parking lots in Indiana, USA, with limited urban applications due to coarse spatial resolution. Several studies using hyperspectral data for urban areas have utilized airborne data acquired by sensors such as DAIS-7915 (ref. 38), AVIRIS $^{33,40,41}$, HyMap $^{34,41}$, HySpex VNIR-1600 (ref. 42), ROSIS $^{43}$ and APEX ${ }^{44}$.

However, with a unique opportunity of the availability of AVIRIS-NG sensor on-board ISRO's B200 aircraft in India, the present study shares the preliminary results of airborne hyperspectral data on retrieval of snow grain size using absorption peak in the NIR in a part of Himalayan region, characterization and identification of urban areas and materials, particularly roof types, and resolution enhancement through super-resolution algorithms for better classification in a part of Ahmedabad city, Gujarat. We discuss the snow and urban sections separately for better clarity and to avoid any intermixing within the individual applications.

\section{Study area and data used}

The Himalayan region is a harsh, with extremely difficult and inaccessible terrain to conduct ground experiments for scientific observations. Chandra-Bhaga basin, located at an altitude ranging from 3000 to $6500 \mathrm{~m}$ in Himachal Pradesh in India, was selected for flying AVIRIS-NG sensor during snow accumulation months. This region experiences cold and dry climate and is mainly fed by western disturbances. Snow remains dry during winter with low density. The AVIRIS-NG flight on 18 and 21 February 2016 covered the region shown in Figure $1 a$ depicting locations of observatories and measuring instruments. Further details on AVIRIS-NG sensor specifications and campaign over India are available in this special section of the journal. Patsio (Bhaga basin) and Dhundi (Beas basin) observatories were chosen to carry out synchronous measurements with spectroradiometer (ASD model Field Pro FR) and collateral datasets. Crystal gauge was used for providing grain size of different types of snow particles, while a thermometer was used for snow surface temperature measurements along with estimating snow density using a density meter. Experiments were conducted on 17 and 18 February 2016.

Ahmedabad, the fifth most populous city in the country, is an important centre of trade and commerce in western India. Morphologically, the city may be considered to comprise three major zones, viz. (1) the inner city, which 

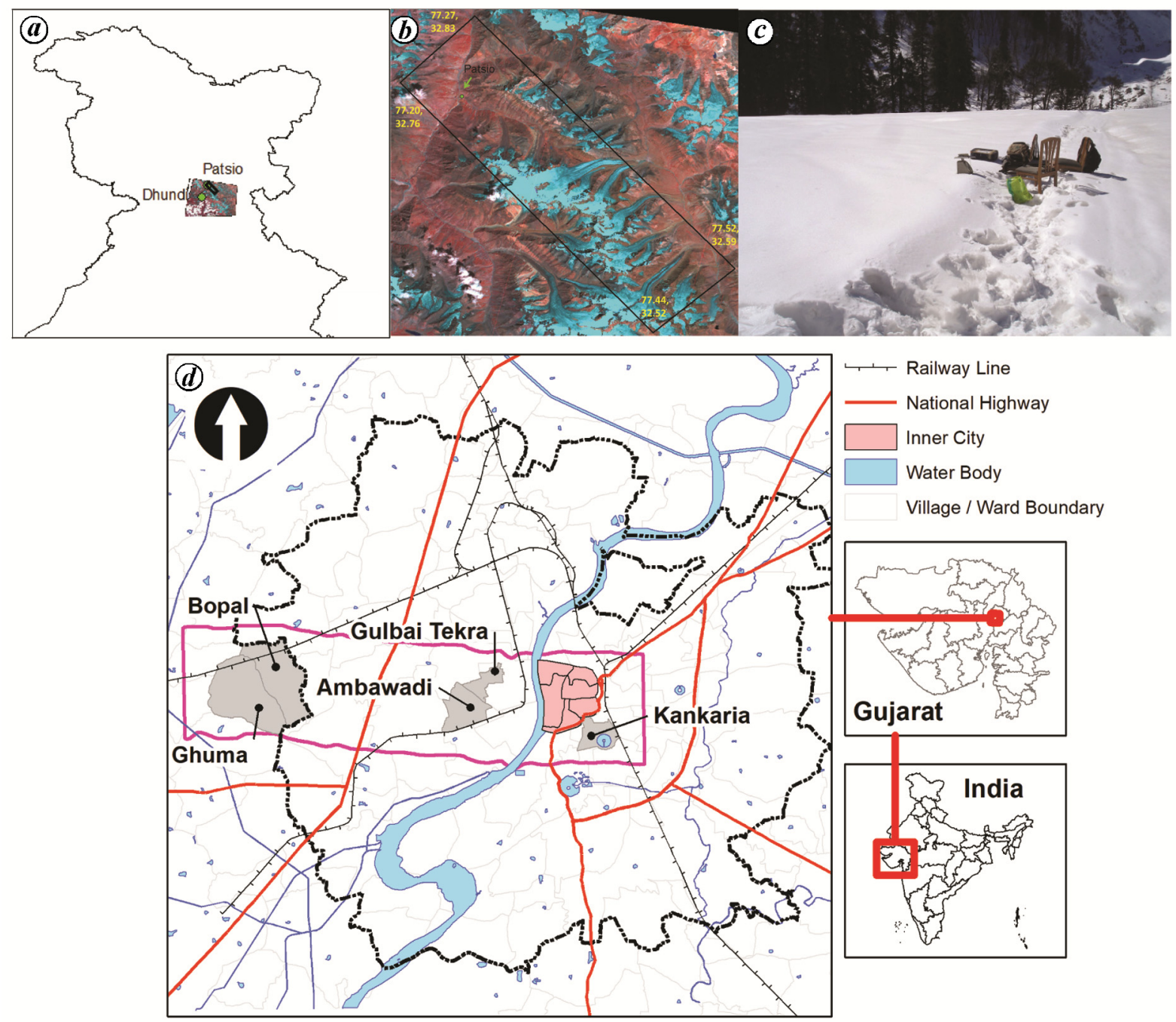

AVIRIS-NG Footprint Municipal Boundary

Town Planning Scheme Boundary

Figure 1. $\boldsymbol{a}$, Location map of Patsio and Dhundi observatories. $\boldsymbol{b}$, LISS-III image with Patsio observatory depicting AVIRIS-NG flight coverage over snow-covered area. $\boldsymbol{c}$, Field photograph showing radiometric and collateral observations at Dhundi observatory. $\boldsymbol{d}$, Map with AVIRIS-NG campaign area covering town planning schemes in urban and sub-urban areas of Ahmedabad city, Gujarat, India.

is also the Central Business District (CBD); (2) eastern Ahmedabad spread on the eastern bank of the Sabarmati River, which also accommodates several industrial estates, and (3) western Ahmedabad sprawling on the western bank of the Sabarmati with predominantly residential and commercial land use. According to the Census of India $^{45}, 72.9 \%$ of buildings in the city have concrete roof, whereas $21.9 \%$ of the roofs comprise galvanized iron (GI), metal or asbestos sheets. The study covers a part of Ahmedabad city extending from the centre to a sub-urban area, thereby providing acquisition over morphologically varied areas. The study included three town-planning schemes each in Bopal and Ghuma villages located in the sub-urban areas of Ahmedabad city, having 1530 plots (land parcels); one town-planning scheme each in Gulbai Tekra and Ambawadi wards in western Ahmedabad having 880 plots, and one townplanning scheme in Kankaria region of eastern Ahmedabad having 480 plots. The town-planning schemes of Bopal and Ghuma villages were prepared by Ahmedabad Urban Development Authority (AUDA), whereas those within municipal limits were prepared by the Ahmedabad Municipal Corporation (AMC). Figure $1 d$ shows the ground coverage of AVIRIS-NG scene (11 February 2016) used in the study over urban area. Super-resolution study was carried out in inner city, covering different urban features.

\section{Methodology}

AVIRIS-NG airborne data provide digital number (DN) values over the targeted area, which is snow cover in this 

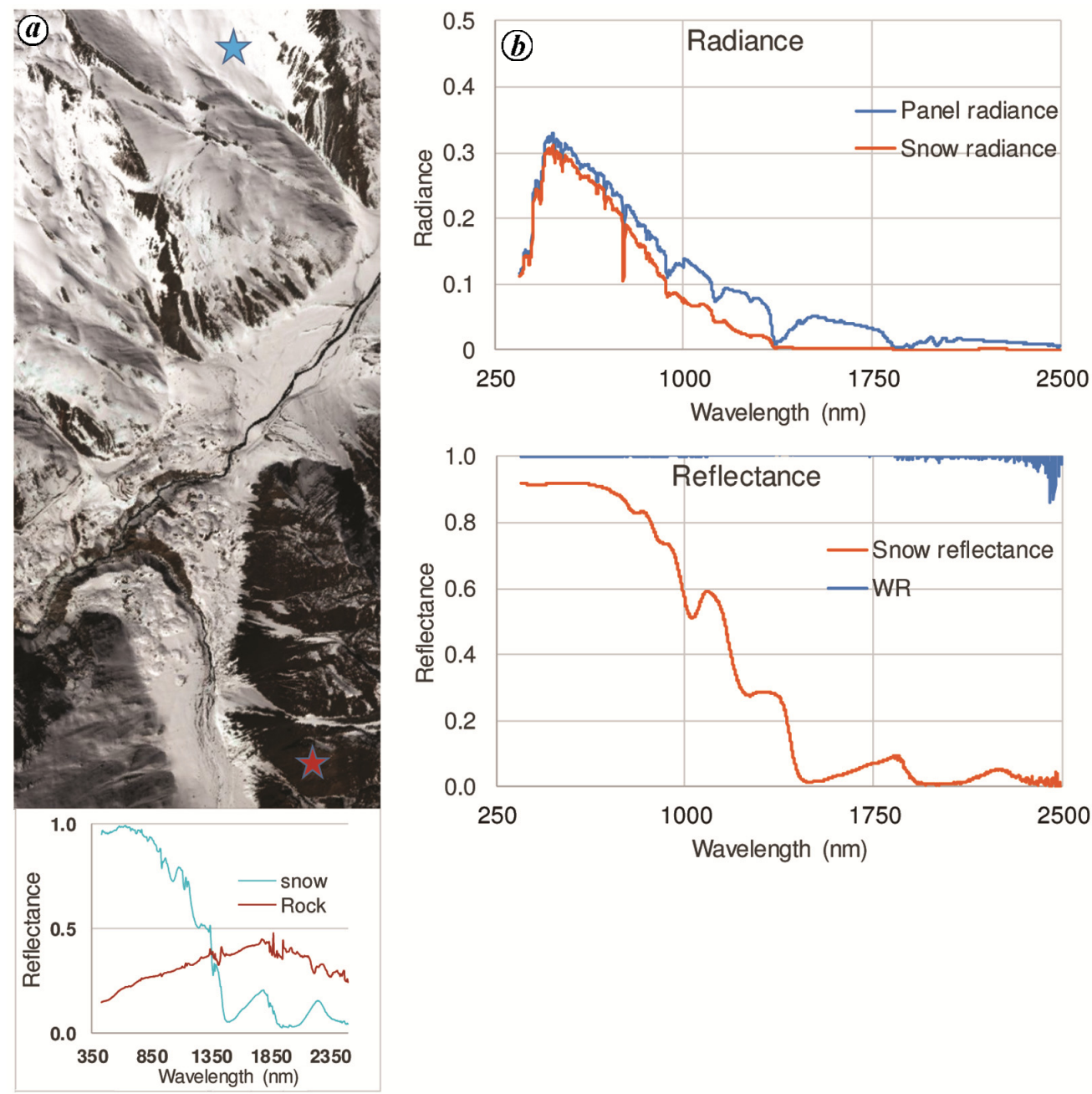

Figure 2. $\boldsymbol{a}$, AVIRIS-NG image acquisition and spectral response of targets over Patsio region; $\boldsymbol{b}$, Field based radiometric measurements of snow in Dhundi (outside image) in the Himalayan region.

case. AVIRIS-NG data were calibrated before the planned flight over different sites for generating calibrated radiometric values for various applications. AVIRIS-NG data were retrieved and radiometrically corrected to convert them into reflectance data, which were used for further analysis. Snow and rock spectra were extracted from AVIRIS-NG image (Figure $2 a$ ). Snow reflectance measurements under different conditions were made at Dhundi synchronous to AVIRIS-NG flight (Figure $2 b$ ). AVIRIS-NG data were extracted for different slope and elevation regions from digital elevation model (DEM) at $12.5 \mathrm{~m}$ generated using ALOS PALSAR data (Figure 3). DEM contour was prepared into 1-16 classes for elevation range from 3500 to $>5700 \mathrm{~m}$ amsl. GI was estimated as shown in eq. (1) ${ }^{16}$, with a threshold to further classify grain size: $<0.2$ as fine grain, $0.2-0.3$ as medium grain and $>0.3$ as coarse grain.

$$
\mathrm{GI}=\frac{\text { Reflectance@590-Reflectane@1050 }}{\text { Reflectance@590+Reflectance@1050 }}
$$

Snow, ice and aerosol radiation (SNICAR) model $^{46,47}$ was used to simulate the effect of grain size on snow reflectance, which works on the concept of Wiscombe and Warren ${ }^{7}$ and utilizing two-stream radiative transfer solutions $^{48}$. SNICAR was used to generate snow reflectance spectra for various grain sizes ranging from 100 to $1500 \mu \mathrm{m}$ (Figure 4). As snow grain size is sensitive to absorption peak at $1030 \mathrm{~nm}$, continuum removal and band depth of the absorption peak was estimated for AVIRIS-NG airborne data, field measurement and modelled data to understand the changes due to varying snow grain size. Snow grain size analysis was carried out only for pure snow pixel. Normalized difference snow index (NDSI) was estimated using visible (green) and SWIR bands, and a threshold of 0.7 was used to identify pure snow pixel. The remaining pixels were masked out from the image.

For urban land cover, sub-pixel analysis on AVIRISNG level-2 data aimed to estimate the proportion of impervious surface and identification of urban targets. The quality of data was compared with respect to in situ 

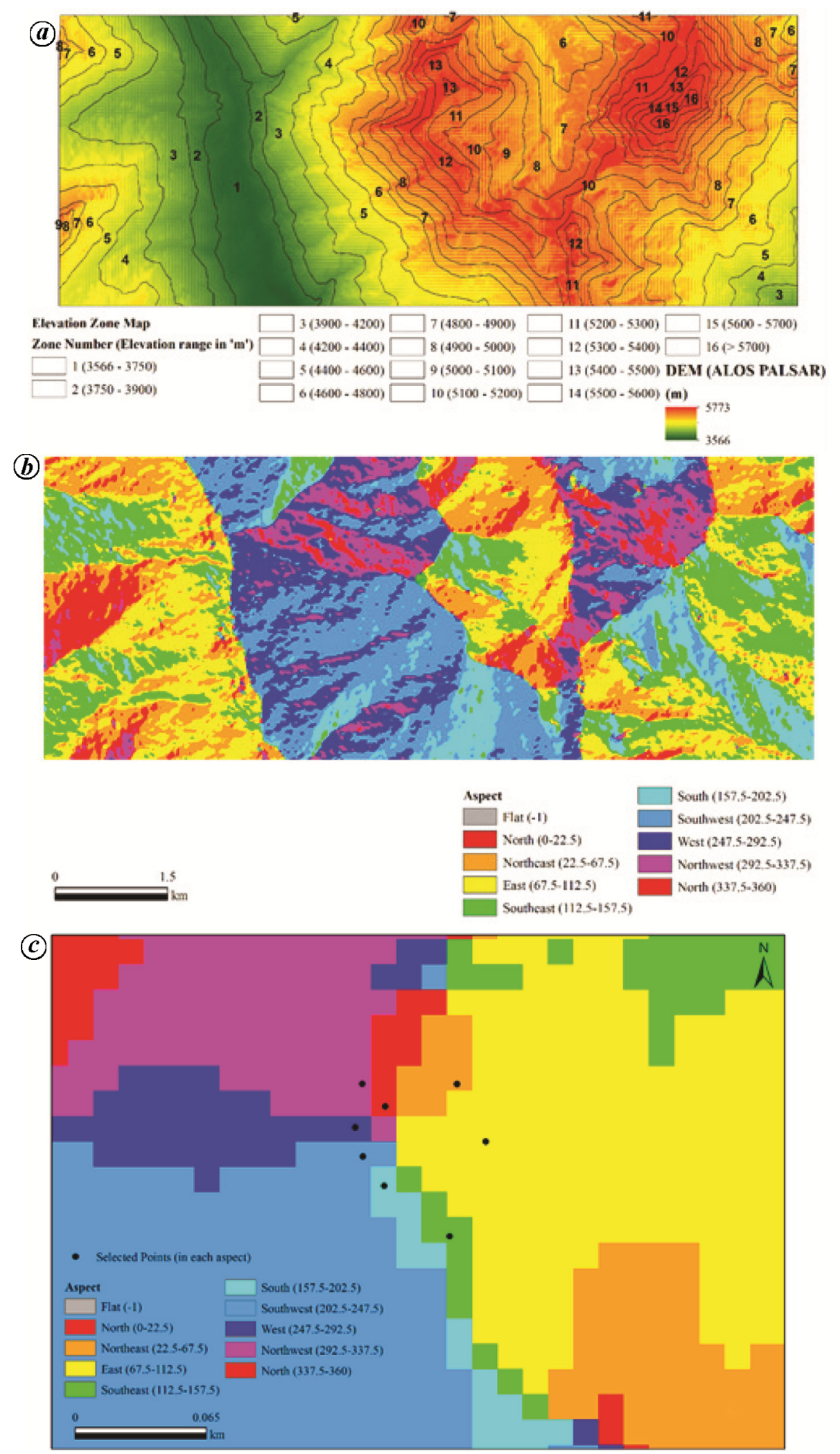

Figure 3. ALOS PALSAR-derived (a) DEM; (b) aspect map, (c) locations (black dots) used in the analysis for the effect of slope and aspect on AVIRIS-NG-derived reflectance.

measurements of the spectral profile of selected urban targets collected from 8 February to 12 February 2016, using HR-1024 spectroradiometer. The fully constrained linear spectral mixture analysis (LSMA) was applied to estimate the abundance of vegetation, soil and impervious surface. Spectral unmixing decomposes a reflectance 

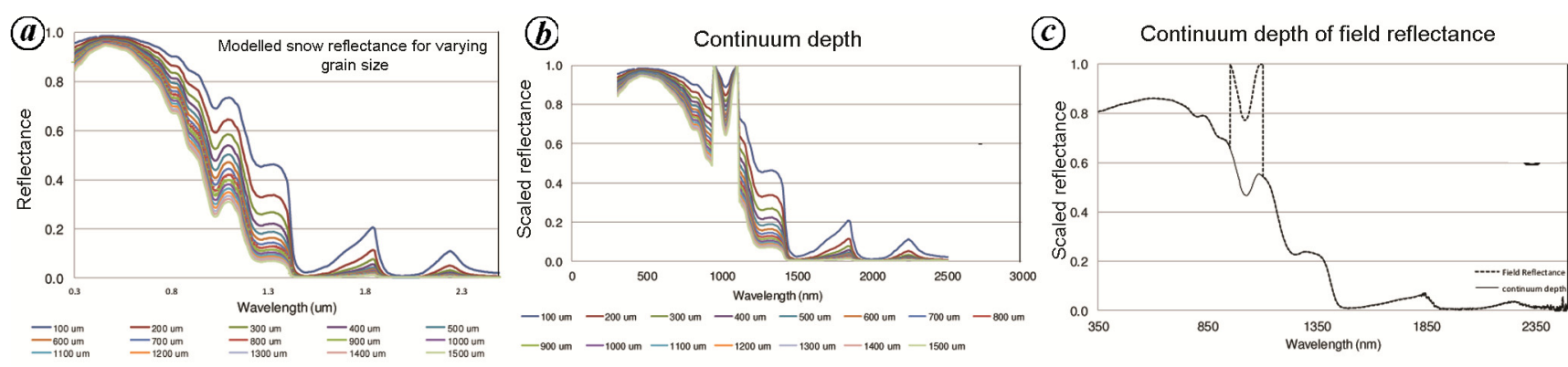

Figure 4. $\boldsymbol{a}$, Snow reflectance modelled for grain size varying from 100 to $1500 \mu \mathrm{m}$. $\boldsymbol{b}, \boldsymbol{c}$, Continuum depth of modelled snow reflectance $(\boldsymbol{b})$ and field data $(c)$ respectively.

source spectrum into a given endmember spectrum as shown in eq. (2).

$$
R_{\lambda}=\sum_{i=0}^{n} a_{i} E_{i, \lambda}+\varepsilon_{\lambda}
$$

where $R_{\lambda}$ is the reflectance of source at wavelength $\lambda, E_{i \lambda}$ the reflectance of endmember $i$ at wavelength $\lambda, a_{i}$ the abundance of endmember $i$ and $\varepsilon_{\lambda}$ is the error at wavelength $\lambda$. Detection of spectrally pure endmembers of specific urban material is difficult and prone to error due to coarse resolution $(8 \mathrm{~m})$ of AVIRIS-NG data, as the size of urban features is much smaller than the pixel size of the data. Thus albedo of impervious surface, largely concrete and bituminous surfaces, was used in the present study.

The spectrally pure and abundant endmembers were selected using the principal component transformation of hyperspectral data into smaller number of prominent bands. It was observed that the low albedo surfaces included water bodies, shadow areas and black-topped road surfaces. The water-body surfaces were therefore masked to estimate total low-albedo impervious surfaces, while assuming that all shadow areas also account for impervious surfaces. The sum of high- and low-albedo surfaces after excluding water bodies, provided the total impervious surface cover at each pixel. Similarly, the sum of soils of agricultural fallow land and vacant urban land provided total fraction of soil cover. The sum of vegetation, soil and impervious surface in each plot in the selected town-planning schemes, multiplied by the area of individual pixels provided total area of vegetation, soil and impervious surface in each land parcel. This was used to estimate the proportion of impervious surface cover in each plot. The $5.8 \mathrm{~m}$ GSD multispectral data of Resourcesat-2 LISS-4 sensor were used for evaluating the results of $8 \mathrm{~m}$ GSD hyperspectral data. LISS-4 image was classified into 36 classes using $K$-means unsupervised classification method, followed by labelling of classes into vegetation, soil and impervious surface cover. Furthermore, in order to validate the results, $10 \%$ of land parcels were selected in urban and sub-urban areas, and impervious surface cover was visually interpreted using Resourcesat-2 LISS-4 image pan-sharpened using Cartosat-2 series PAN image. The Brovey method was used to fuse Cartosat-2 panchromatic image with Resourcesat-2 LISS-4 multispectral image. The results were compared to assess the effectiveness of LSMA in estimating impervious surface cover. The areas with very high root mean square error (RMSE) were further analysed to identify the possible existence of materials other than concrete and bitumen in impervious surface. This was accomplished by choosing all pixels with an empirically selected threshold of RMSE greater than 0.035 . These pixels were converted into spectral endmembers and the corresponding spectral profile was extracted from AVIRIS-NG image. The spectral angle was computed using eq. (3) between each of these endmembers.

$$
\theta_{x y}=\cos ^{-1}\left(\frac{\sum_{i}^{n} x_{i} \times y_{i}}{\sqrt{\left(\sum_{i}^{n} x_{i}^{2}\right)\left(\sum_{i}^{n} y_{i}^{2}\right)}}\right),
$$

where $\theta_{x y}$ is the spectral angle between $x$ and $y$ endmembers (radians), and $x_{i}, y_{i}$ are the spectral measurements of the $i$ th band. The materials were thereafter grouped according to their angles and spectral profiles were compared with the spectral library. The spectrally distinct endmembers thus obtained were used to apply spectral angle mapper (SAM) for identification of materials in the study area. Furthermore, very high spatial resolution Google Earth images with sub-metre resolution of the closest available date were used to compare the results on $10 \%$ of the classified pixel locations (maximum limited to 50 locations), selected randomly, for each of the endmembers to assess the quality of material detection.

Resolution enhancement by super-resolution approach consisted of data pre-processing, resolution enhancement by super-resolution, and comparative analysis and validation using quality metrics. Figure 5 is a flow chart showing the detailed methodology. Data pre-processing includes sensor error correction, spatial subset for extraction of the study area and spectral subset for preparation 


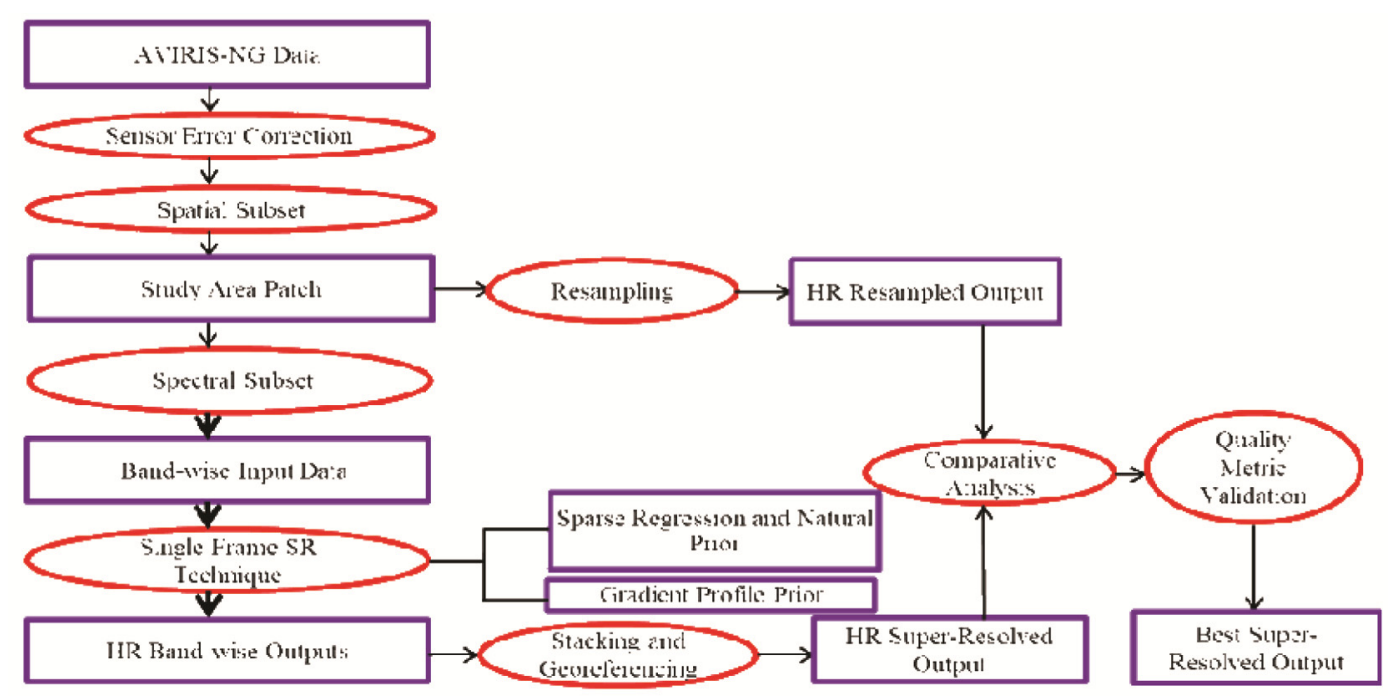

Figure 5. Methodology for resolution enhancement by super-resolution over urban area.

of band-wise input data for performing single-frame super-resolution. Sparse regression and natural prior (SRP) and gradient profile prior (GPP) have been used for resolution enhancement. These methods were chosen on the basis of robust visual quality of output, faster computational time and ability to recover accurate spectral and spatial characteristics of the input as reported in the literature. The methods have been executed by modifying the freely available source codes in MATLAB. The super-resolved outputs generated using the abovementioned methods were compared among themselves as well as with the reference image, both visually and statistically. Six points corresponding to different features such as road junction, building, railway track, dense urban settlement and vegetation were chosen up for visual inspection. Eight indices were used, among which five measured spatial quality while the remaining three checked the spectral quality. Bias, correlation coefficient (CC), difference in variance (DIV), entropy and RMSE are the spatial, while errur relative globale adimensionnelle de synthese (ERGAS), relative average spectral error (RASE) and universal image quality index $(Q)$ are spectral in nature. Evaluation of quality metrics was performed using freely available toolbox hyperspectral image index analysis (developed by Aristidis Vaiopoulos in MATLAB R2017b Student Version).

\section{Results and discussion}

AVIRIS-NG sensor-derived reflectance provides the contiguous spectral signature of different land-cover types (snow and urban targets in this case), which shows the effect of varying physical properties in different parts of the EM spectrum. These changes in the spectrum has been used to retrieve the respective physical properties based on their spectral characterization in snow and urban classes. Figure 2 a shows a false colour composite (FCC) of bands 87,45 and 25 (862, 651 and $551 \mathrm{~nm}$ respectively) over Patsio area in the Himalayan region. Reflectance spectra of two targets from the image, i.e. snow and rock shows typical signatures of both. Figure $2 b$ shows the radiance and reflectance measurements over Dhundi observatory during the air-borne flight, and snow reflectance from image and ground observation can be visualized.

AVIRIS-NG-derived reflectance on different slopes shows higher magnitude reflectance for southern-oriented slope, maximum for SE, whereas low magnitude for northern-oriented slope, minimum for NW (Figure 6), as reported from ground measurements ${ }^{16}$. Figure 7 depicts the retrieval of grain size using GI technique into three major classes, i.e. fine, medium and coarse, overlaid by height contours from zone 1 to 16 . It shows dominance of fine snow grain size in the image, which is also expected in this region during February due to frequent fresh snowfall and low temperature conditions. Another approach based on absorption peak depth at $1030 \mathrm{~nm}$ was used to retrieve more classes of snow grain.

As shown in Figure $4 a$, snow reflectance was modelled for grain size varying from 100 to $1500 \mu \mathrm{m}$. It can be observed that changed grain size influences NIR and longer wavelength region. Continuum depth of modelled reflectance is shown in Figure $4 b$ using absorption depth at NIR and has been used to retrieve grain size of snow. Figure 8 depicts the extracted snow reflectance of pixel from AVIRIS-NG image and respective absorption peak after continuum removal centred at $1030 \mathrm{~nm}$. AVIRISNG image was classified based on variation in depth of absorption peak at identified NIR (Figure $9 a$ ). Figure $9 b$ shows the variability within grain classes based on absorption depth. Figure $9 c$ and $d$ depicts the AVIRISNG image of absorption depth variability at NIR, which 


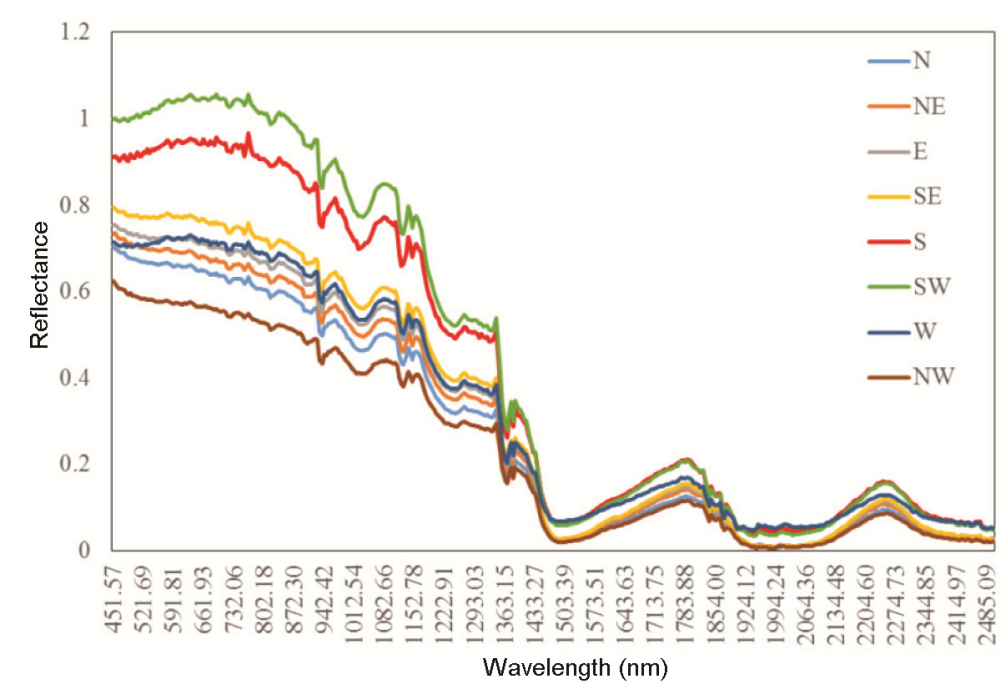

Figure 6. Variation in magnitude of reflectance spectra of snow for different aspects.

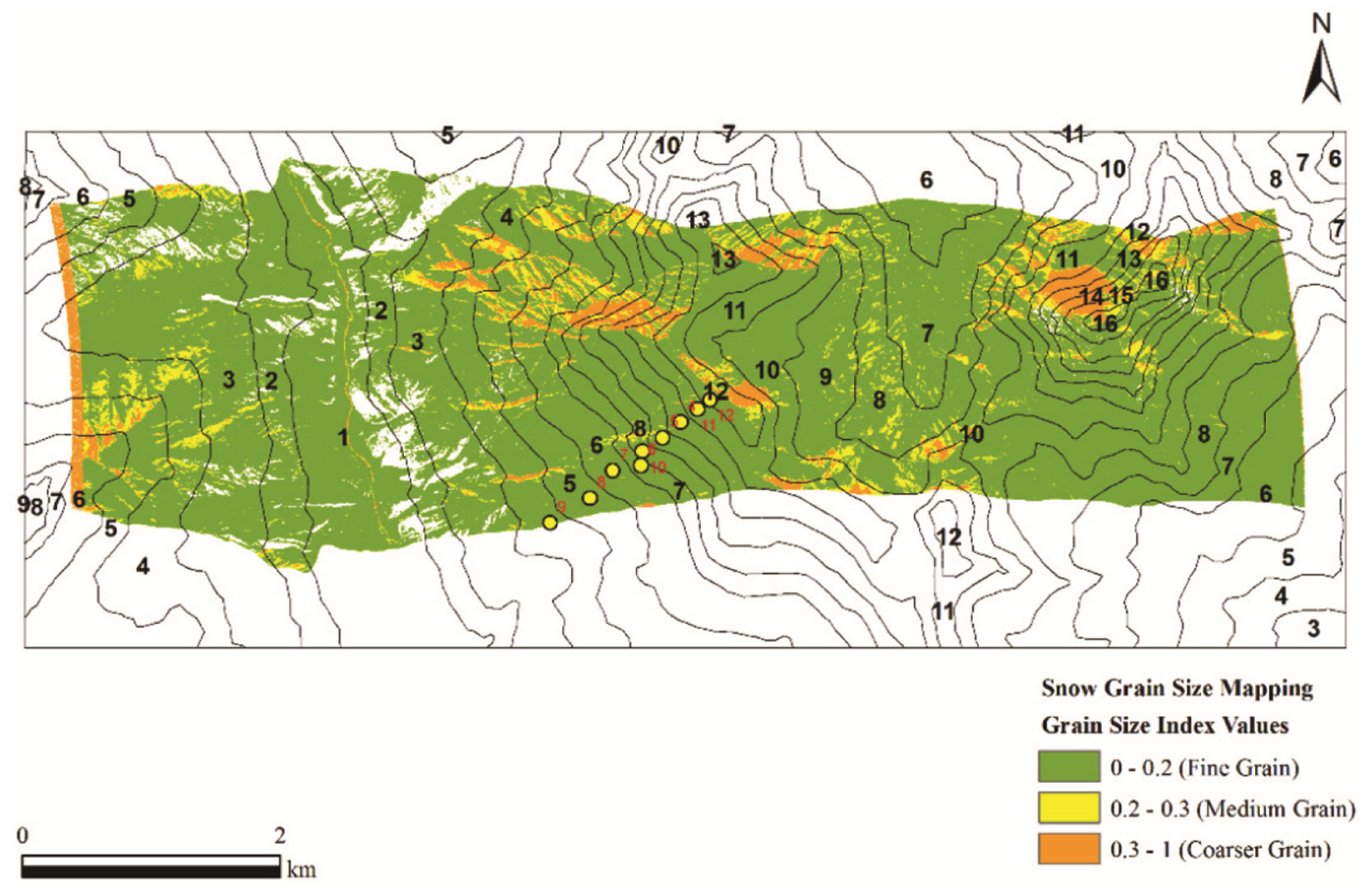

Figure 7. Snow grain size distribution using grain index and its variability with elevation zone.

shows increase in grain size variability in the hilly terrain. Profile across the valley shows fluctuations in grain size (Figure $9 e$ ). Majority of region is covered under fine to medium snow grain size and shows improved quantitative retrieval over GI approach. Continuum depth at $1030 \mathrm{~nm}$ of field data in Dhundi was estimated 0.226 (Figure $4 c$ ) which was close to continuum depth of snow grain modelled at $500 \mu \mathrm{m}$ as depicted in Figure $4 a$. Temperature at lower altitudes is relatively high, which introduces liquid water content between ice crystals as they descend, leading to change in grain size while precipitating and depositing on ground. This supports the observations, as
Dhundi falls in the lower altitude region in comparison to Patsio observatory.

In the urban section, Ahmedabad building roofs are usually covered by mosaic of broken ceramic tile pieces arranged either randomly or in specific patterns, over a layer of white cement paste known as China mosaic. The resulting surface has very high reflectance. In older buildings, the China mosaic treatment is not prevalent; instead the concrete surfaces are left bare with smooth finishing, with or without any water-proofing treatment or white paint. The aging of concrete, however, results in decrease in its reflectance. The low-albedo surfaces include 

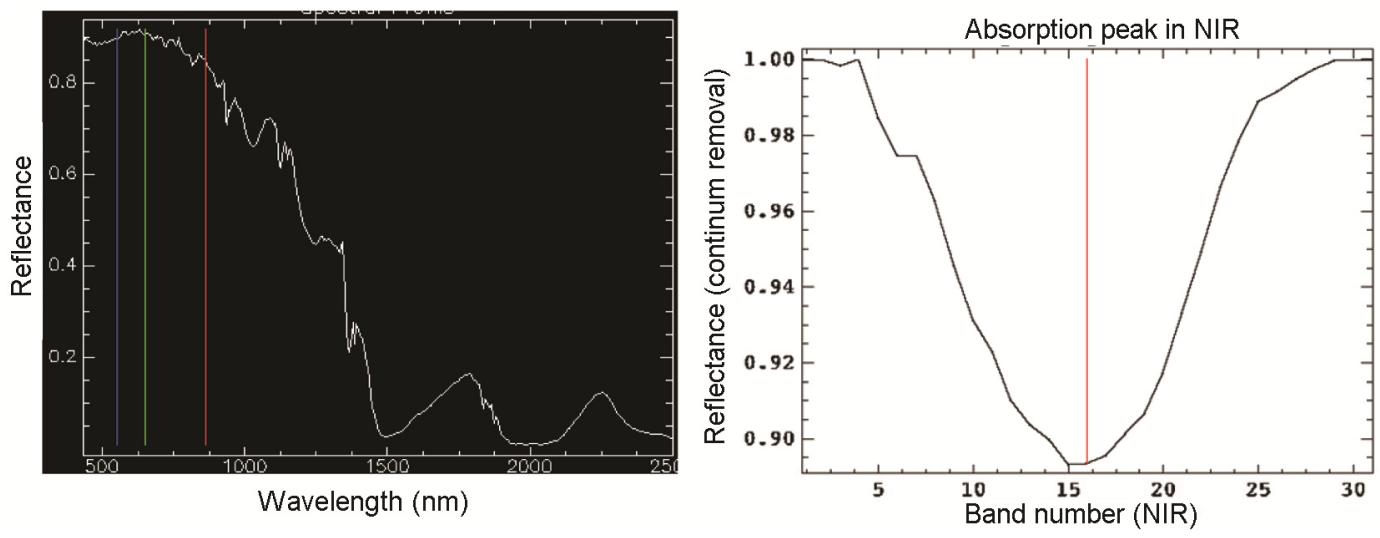

Figure 8. Reflectance spectra of snow pixel from image and absorption peak after continuum removal at $1030 \mathrm{~nm}$.

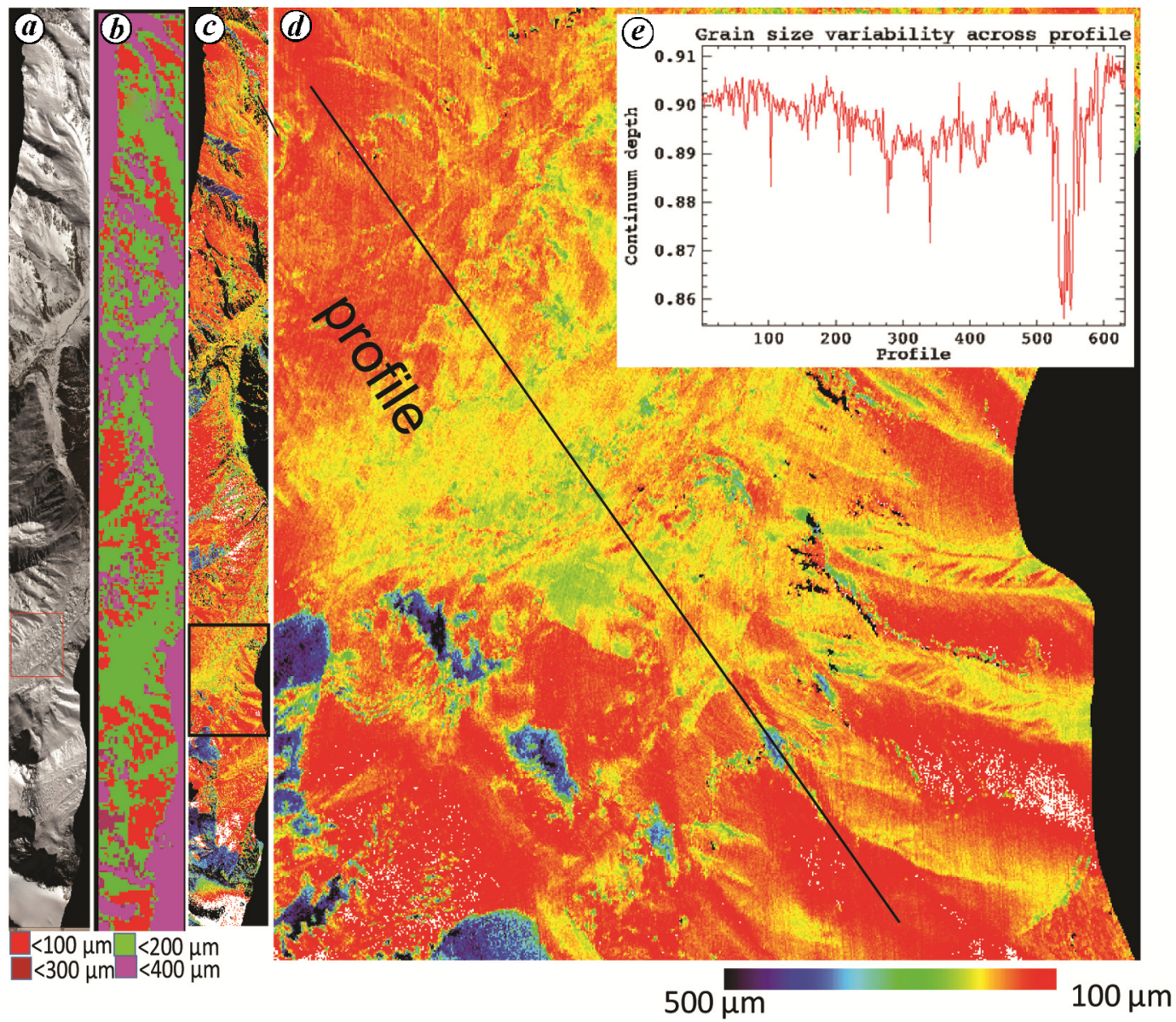

Figure 9. $\boldsymbol{a}$, AVIRIS-NG image; $\boldsymbol{b}$, grain size class map (legend below the strip); $\boldsymbol{c}$, absorption depth variability in the image; $\boldsymbol{d}$, profile over a part of AVIRIS-NG image (black rectangle in $(\boldsymbol{c})$ ); $\boldsymbol{e}$, variation of absorption depth of profile.

bituminous surfaces of black-topped roads. As the study area extends to adjoining agricultural land, the endmembers of bare soil included agricultural fallow land and vacant land. The spectral signature of fallow land includes characteristics of non-photosynthetic vegetation, with lignocellulose vibrational absorption near 2100 and $2300 \mathrm{~nm}$ wavelength ${ }^{33}$ (Figure 10). The vacant soils are however devoid of non-photosynthetic vegetation and are usually covered with sandy soil, thereby resulting in high-albedo surfaces.

The study area is dominated by impervious surface cover (Figure 11), that accounts for $49.19 \%$ of the total study area, whereas fraction of land covered by soil and vegetation in the study area is $39.87 \%$ and $8.31 \%$ 
respectively. The remaining area is covered by water bodies, which were extracted separately. The mean RMSE of LSMA was 0.0072 , with over $80 \%$ of pixels having error less than $0.001 \%$ and $99.76 \%$ pixels having error less than 0.035. It is apparent that the areas in eastern Ahmedabad (including the inner city) and non-urban areas in the sub-urban regions of the city have relatively higher RMSE. Eastern Ahmedabad is dominated by low-albedo impervious surfaces resulting from a dense network of narrow streets, ageing concrete roofs occasionally covered with tin sheds, tarpaulin sheets and a variety of other materials, and shadows of buildings. Similarly, the diversity in vegetation along with water present in the fields causes high RMSE in agricultural land in the study area.

Figure 12 shows the proportion of impervious surface cover at plot level in the sub-urban areas of Bopal and Ghuma villages and the urban areas of eastern and western Ahmedabad city. It is apparent that the average proportion of impervious surface cover in sub-urban areas is around $40 \%$, whereas that in eastern and western Ahmedabad is $50 \%$ and $55 \%$ respectively. The results were compared with the estimation of impervious surface from Resourcesat-2 LISS-4 data. The impervious surface

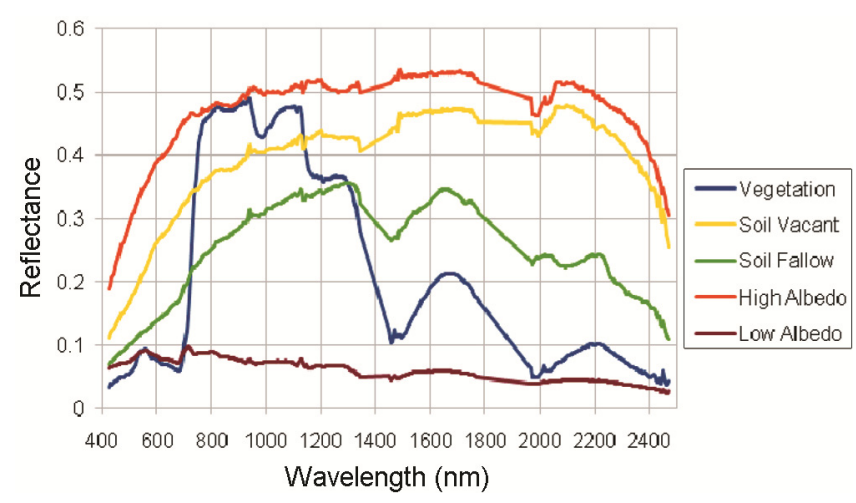

Figure 10. Endmembers extracted with AVIRIS-NG using linear spectral mixture analysis.

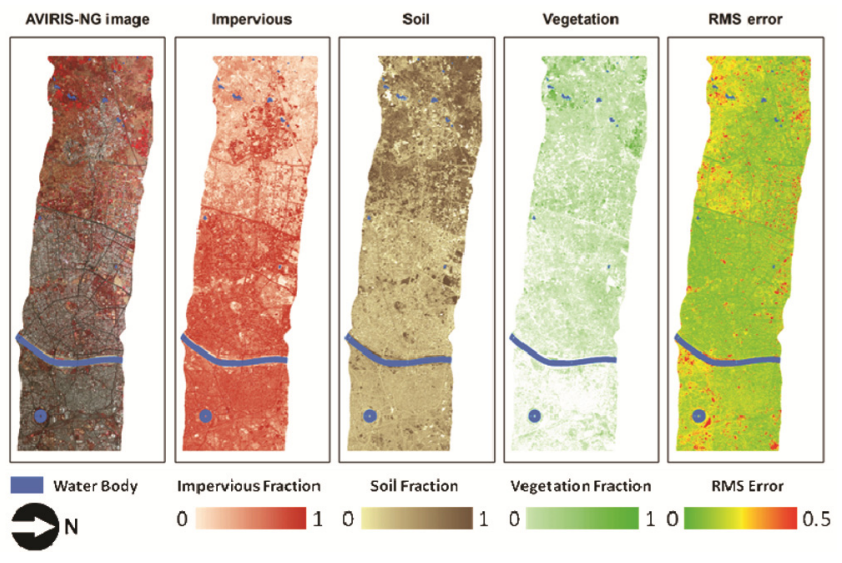

Figure 11. Fraction of vegetation, soil and impervious surface in AVIRIS-NG image over urban area. cover in the sub-urban areas of Bopal and Ghuma as estimated from LISS-4 image was observed at 19\%, whereas that in the urban areas of Gulbai TekraAmbawadi and Kankaria areas were 59\% and $77 \%$ respectively. The primary cause for substantial difference in estimation of impervious surface cover in sub-urban areas is error from low-albedo surfaces, particularly the shadow regions and water. The greater variation in impervious surface cover in Kankaria region is due to existence of very old buildings, different roof types and smaller plot sizes. The median plot size in the townplanning scheme of Kankaria is 615.08 sq. $\mathrm{m}$, whereas that in Gulbai Tekra and Ambawadi town-planning schemes is 899.30 sq. $\mathrm{m}$. The area also consists of few large plots with buildings having asbestos concrete roof sheds, which are misclassified. Moreover, the unsupervized classification of LISS-4 image has inherent errors, particularly in separating vacant land and impervious surfaces. The impervious surface cover was also visually interpreted using Cartosat-2 PAN and Resourcesat-2 LISS4 merged product on $10 \%$ of the plots in each of the three study zones. It was observed that average impervious surface cover as computed using LISS-4 data, AVIRIS-NG data and Cartosat-2 + LISS-4 merged product on the urbanized plots in Bopal and Ghuma villages was 23.07\%, $43.86 \%$ and $41.47 \%$ respectively. The AVIRIS-NG data showed better concurrence with very high spatial resolution data in plots with higher proportion of impervious surface cover. In Gulbai Tekra-Ambawadi town-planning schemes of western Ahmedabad, the average proportion of impervious surface cover on sample of plots as derived from LISS-4, AVIRIS-NG and Cartosat-2 + LISS4 data was $58.92 \%, 65.28 \%$ and $65.44 \%$ respectively. In case of Kankariya, it was $88.19 \%, 70.79 \%$ and $62.20 \%$ respectively. It is therefore evident that hyperspectral data have better classification accuracy in the estimation of impervious surface cover than multispectral data of LISS-4. The mixed-pixel problem in multispectral data results into overestimation of impervious surface cover in densely built areas and under classification in sparsely built areas.

The spectral profiles of pixels with RMSE greater than 0.035 were analysed to identify specific urban materials that are not represented by common endmembers using in LSMA. The study identified 94 contiguous regions within the image with minimum patch area of 300 sq. m (approximately $2 \times 2$ pixels). The spectral profiles of these objects were compared using spectral angle and specific urban materials were identified. The study was able to detect blue-coloured and white-coloured tarpaulin sheets, plastic fibre sheets, marble stone, corrugated asbestoscement sheets, corrugated GI sheets and blue ceramic tiles of swimming pools. The plastic materials used for roofs or temporary sheds could be identified using distinct spectral reflectance curves. The white tarpaulin sheets used to make temporary sheds showed absorption features at $1658 \mathrm{~nm}$; which correspond to that of polythylene 

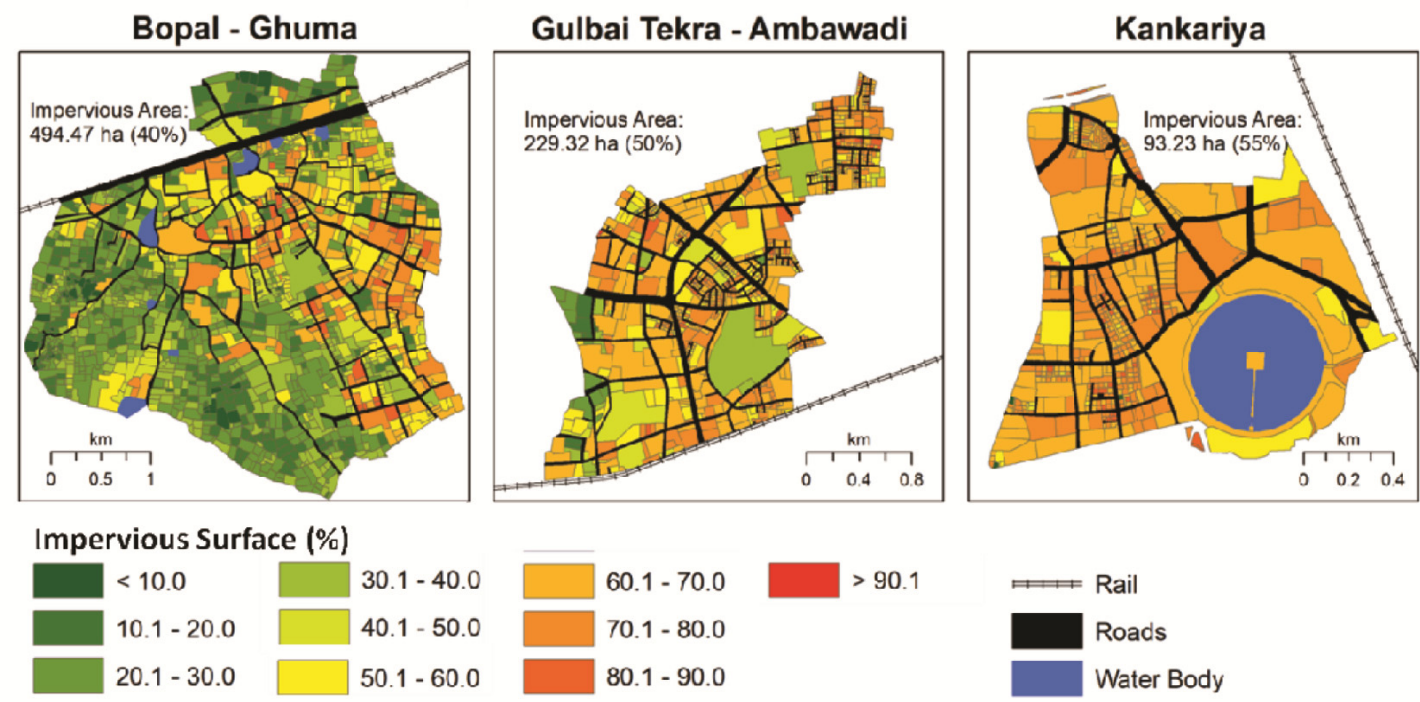

Figure 12. Impervious surface proportion in urban and sub-urban areas.

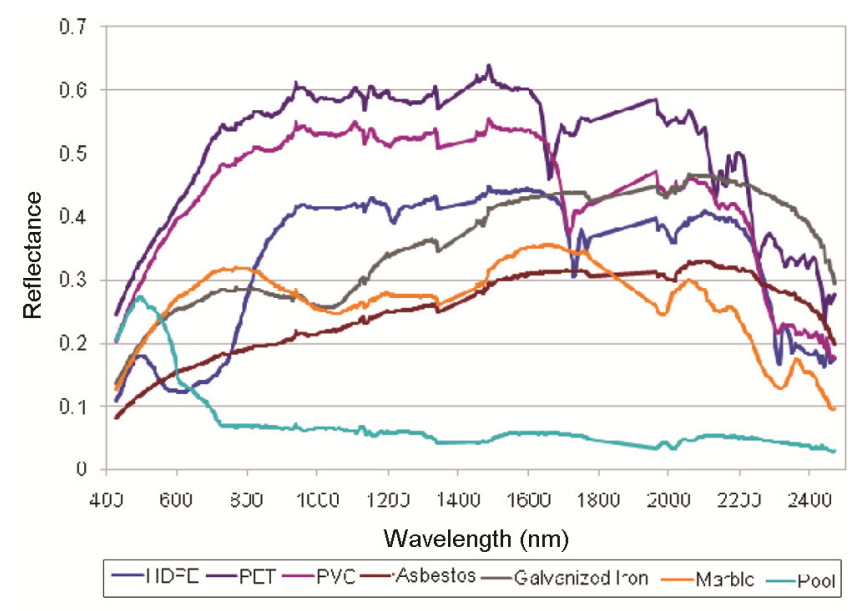

Figure 13. Spectral profiles of selected urban materials.

terephthalate (PET) polyester material. The blue-coloured tarpaulin sheets showed absorption features at 1729 and $1764 \mathrm{~nm}$, which corresponds to high density polythelene (HDPE) material. Plastics are also used in roofs of several buildings, either in combination with concrete roofs or independently. The spectral profiles of plastic roofs showed valley point at $1713 \mathrm{~nm}$, which corresponds to polyvinyl chloride (PVC) material. In industrial buildings, the use of corrugated sheets of GI and asbestos cement is predominant. GI sheets showed a distinct absorption feature near $1020 \mathrm{~nm}$. The asbestos cement corrugated sheets have reflectance similar to soil and concrete roofs. However, studies have shown its separability in SWIR region of the spectrum. The asbestos cement roofing material showed an absorption feature at $2327 \mathrm{~nm}$. Bonifazi et al $^{49}$ reported presence of absorption region in the wavelength range $2320-2340 \mathrm{~nm}$ cor- responding to $\mathrm{Fe}-\mathrm{OH}$ and $\mathrm{Mg}-\mathrm{OH}$ combination bands, while the cement matrix binding the asbestos fibres showed absorption at $2350 \mathrm{~nm}$. Marble stone, typically used as flooring in religious structures such as mosques, showed absorption features corresponding to iron bands and carbonate bands (ferroan calcite) at 1050 and $2315 \mathrm{~nm}$ respectively ${ }^{50,51}$. Swimming pools showed low reflectance in all wavelengths, other than visible. Figure 13 shows the spectral profiles of these materials as obtained from the image. The materials identified from the analysis of RMSE in LSMA of AVIRIS-NG image were further used as endmembers for SAM. Figure 14 shows the results of SAM for detection of roofs composed of blue tarpaulin sheets, white tarpaulin sheets, plastic roof sheds, asbestos cement sheds and GI sheds.

The super-resolved outputs generated had a spatial resolution of $4.05 \mathrm{~m}$. Figure 15(i) shows the enlarged version of patches in the reference image as well as the super-resolved outputs. Visual inspection reveals that water has a smooth and fine texture with little to no tonal variation in all the super-resolved outputs of Nagina Wadi. It can also be seen that the edges of vegetation patch are delineated, with clear distinction between grasses and thick tree cover inside the patch in both super-resolved outputs (Figure 15, ii). Road and its width are clearly delineated in the super-resolved outputs (Figure 15, iii). Other features such as dense built-up area, open area and vegetation are also delineated, although sharpness of edges is lost (Figure 15, iii). In both SRP and GPP outputs (Figure 15, iv), the railway tracks along with edges are distinguishable. Road passing through dense built-up area is retrieved in the super-resolved outputs (Figure 15, v) and edges of building are preserved in all outputs (Figure 15 , vi). Even the tone of SRP output resembles the reference image (Figure 15, vi). 


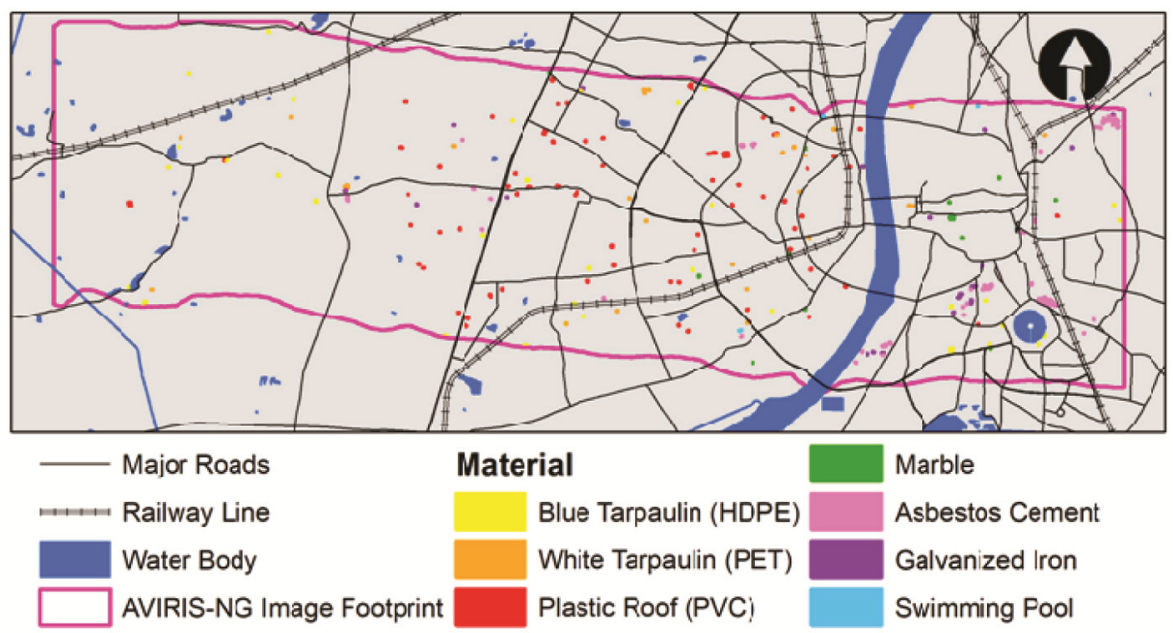

Figure 14. Urban material identification using spectral angle mapper over AVIRIS-NG data.
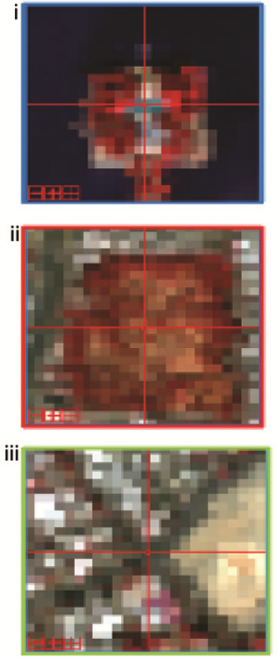

Reference
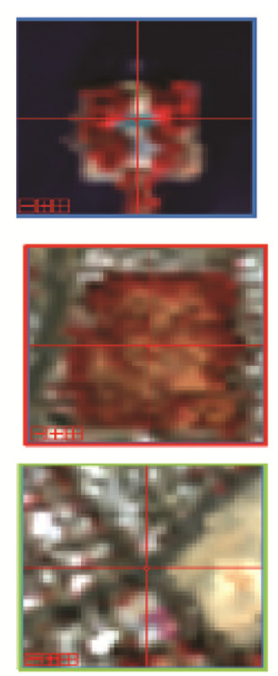

SRP output
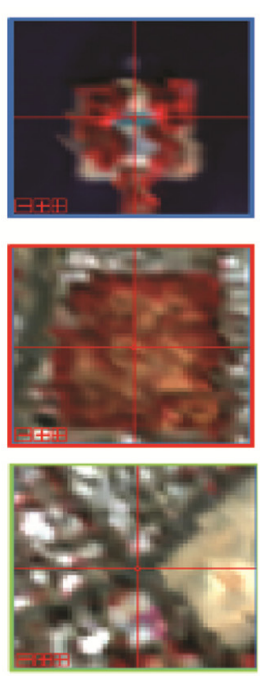

GPP output
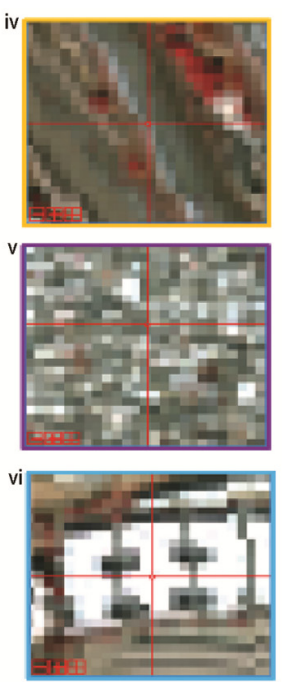

Reference
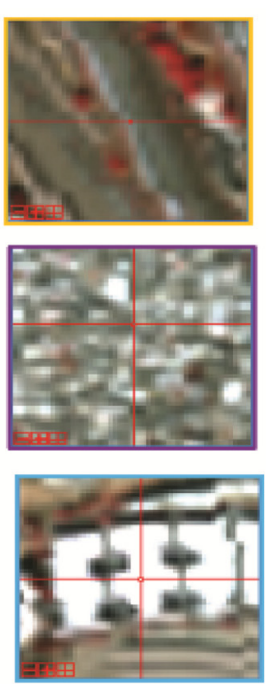

SRP output
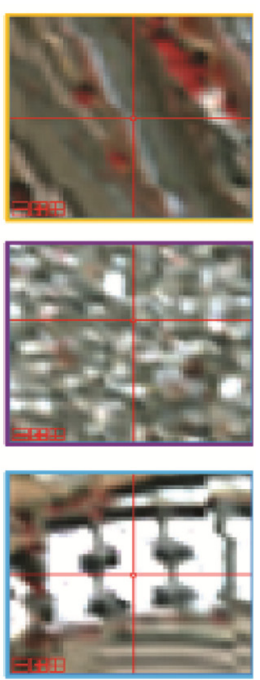

GPP output

Figure 15. Enlarged version of patches in reference image and super-resolved outputs.

Maximum value, minimum value, arithmetic mean and standard deviation values were obtained for each band in the image, which were averaged (Table 1). The statistical analysis is indicative of the fact that every superresolution technique brings about minor changes in the mean value. Thus there techniques are successful in retaining spatial fidelity. There are little changes in maximum and minimum values from that of reference image, i.e. Resampled_NN in case of both super-resolved outputs, i.e. Output_SRP and Output_GPP. This suggests a strong resemblance of these outputs to the reference. This fact is also indicated by lower fluctuation in the values of standard deviation with respect to reference image for both outputs. It is worth mentioning that SRP should be the first choice in index analysis due to least variation in its statistical values from the reference image. One of the best ways to assess the efficiency of any process is to determine the time taken by it to generate the output. It can be observed that SRP takes the least time $(0.173 \mathrm{~s})$ to generate super-resolved output, while GPP takes maximum time (94.132 s) for generating the super-resolved output. Lowest RMSE values are those of output generated by SRP, indicating strong resemblance with the reference imagery. Both methods have $\mathrm{CC}$ and $Q$ values above 0.9 , indicating good preservation of feature information at higher spatial resolution. Highest $\mathrm{CC}$ and $Q$ values are those of output generated by SRP followed by GPP. The output generated by SRP has recorded a very small positive value of DIV and is mostly representative of the reference imagery. GPP has a very small negative DIV value and hence it also bears strong resemblance with the reference imagery. However, if absolute values are considered, then DIV value of GPP is the lowest and hence it is the best performing technique followed by SRP. Lowest values of ERGAS and RASE are in case of output generated by SRP, which indicates high preservation of spectral information. Therefore, SRP is the best performing technique in preserving spectral 
Table 1. Quality metric validation results

\begin{tabular}{|c|c|c|c|c|c|c|c|c|}
\hline Approach & $\begin{array}{c}\text { Average } \\
\text { bias }\end{array}$ & $\begin{array}{l}\text { Average } \\
\text { difference } \\
\text { in variance }\end{array}$ & $\begin{array}{l}\text { Average } \\
\text { correlation } \\
\text { coefficient }\end{array}$ & $\begin{array}{l}\text { Average } \\
\text { entropy }\end{array}$ & $\begin{array}{l}\text { Average errur } \\
\text { relative globale } \\
\text { adimensionnelle } \\
\text { de synthese }\end{array}$ & $\begin{array}{c}\text { Average } \\
\text { universal } \\
\text { image } \\
\text { quality index }\end{array}$ & $\begin{array}{l}\text { Average } \\
\text { relative } \\
\text { average } \\
\text { spectral error }\end{array}$ & $\begin{array}{c}\text { Average } \\
\text { root mean } \\
\text { square error }\end{array}$ \\
\hline SRP output & 0.0 & 0.07 & 0.98 & 12.59 & 4.08 & 0.98 & 8.15 & 0.01 \\
\hline GPP output & 0.0 & -0.02 & 0.96 & 13.38 & 5.25 & 0.96 & 10.49 & 0.02 \\
\hline Resampled output (NN) & 0.0 & 0.0 & 1.0 & 13.47 & 0.0 & 1.0 & 0.0 & 0.0 \\
\hline
\end{tabular}

information. Highest value of entropy is in case of output generated by GPP, indicating addition of maximum information to the output. Lowest value is in the case of SRP indicating loss of information in the output, which is contrary to the results of other index analyses. Therefore, index analysis results clearly show that SRP is the best performing technique, while GPP is the worst performing technique.

\section{Conclusion}

This study explored the potential of hyperspectral data for snow and urban applications, particularly for retrieval of snow grain size using modelled, ground and satellite data, estimation of impervious surfaces and identification of urban materials. AVIRIS-NG-derived reflectance on different slopes have showed higher magnitude reflectance for southern-oriented slope, maximum for SE, whereas lower magnitude for northern-oriented slope, minimum for NW. Snow grain size retrieval was done using two approaches based on absorption peak at NIR and grain index, which have shown the presence of fine to medium snow grain over the study area. The AVIRISNG hyperspectral data were able to estimate impervious surface cover in urban and sub-urban areas with better accuracy than the multispectral data acquired by LISS-4 sensors. It was, however, observed that the spatial resolution of $8.1 \mathrm{~m}$ is not sufficient for urban areas, as the scale of urban objects is much smaller and the material composition in urban areas is heterogeneous, as observed in densely populated regions of eastern Ahmedabad. SRP showed the best results in terms of visual quality, statistics as well as computational efficiency, which is validated by the values of different spatial and spectral metrics as well. It is therefore evident that hyperspectral data are useful for snow and urban land-cover applications, and provide more insights for better utility of it is therefore evident that frequent hyperspectral observations from space will play a major role in providing inputs to understand various facets of snow and urban land covers applications.

1. Kulkarni, A. V., Singh, S. K., Mathur, P. and Mishra, V. D., Algorithm to monitor snow cover using AWiFS data of RESOURCESAT-1 for the Himalayan region. Int. J. Remote Sensing, 2006, 27, 2449-2457.
2. Hall, D. K., Riggs, G. A., Salomonson, V. V., DiGirolamo, N. and Bayr, K. J., MODIS snow cover products. Remote Sensing Environ., 2002, 83, 181-194.

3. Singh, S. K., Rathore, B. P., Bahuguna, I. M. and Ajai, Snow cover variability in the Himalayan-Tibetan region. Int. J. Climatol., 2014, 34, 446-452; doi:10.1002/joc.3687.

4. Rathore, B. P. et al., Trends of snow cover in Western and WestCentral Himalayas during 2004-2014. Curr. Sci., 2018, 114(25), $800-807$.

5. O'Brian, H. W. and Munis, H., Red and near-infrared spectral reflectance of snow. U.S. Army Cold Regions Research \& Engineering Laboratory, Res. Rep., 1975, No. 332, p. 18.

6. Warren, S. G. and Wiscombe, W. J., A model for the spectral albedo of snow - II: snow containing aerosols. J. Atmos. Sci., 1980, 37, 2734-2745.

7. Wiscombe, W. J. and Warren S. G., A model for the spectral albedo of snow I: pure snow. J. Atmos. Sci., 1980, 37, 2712-2733.

8. Colbeck, S. C., Grain clusters in wet snow. J. Colloid Interface Sci., 1979, 72(3), 371-384.

9. Hyvärinen, T. and Lammasniemi, J., Infrared measurement of free-water content and grain size of snow. Opt. Eng., 1987, 26(4), 342-348.

10. Nolin, A. W. and Dozier, J., Estimating snow grain size using AVIRIS data. Remote Sensing Environ., 1993, 44, 231-238.

11. Nolin, A. W. and Dozier, J., A hyperspectral method for remotely sensing the grain size of snow. Remote Sensing Environ., 2000, 74, 207-216.

12. Nolin, A. W., Recent advances in remote sensing of seasonal snow. J. Glaciol., 2010, 56(200), 1141-1150.

13. Dozier, J. and Painter, T. H., Multispectral and hyperspectral remote sensing of alpine snow properties. Annu. Rev. Earth Planet. Sci., 2004, 32, 465-494; doi 10.1146/annurev.earth.32. 101802.120404.

14. Singh, S. K., Kulkarni, A. V. and Chaudhary, B. S., Hyperspectral analysis of snow reflectance to understand the effects of contamination and grain size. Ann. Glaciol., 2010, 54(44), 83-88.

15. Singh, S. K., Kulkarni, A. V. and Chaudhary, B. S., Spectral characterization of soil and coal contamination on snow reflectance using hyperspectral analysis. J. Earth Syst. Sci., 2011, 120(2), 321-328.

16. Negi, H. S., Singh, S. K., Kulkarni, A. V. and Semwal, B. S., Field based spectral reflectance measurements of seasonal snow cover in Indian Himalaya. Int. J. Remote Sensing, 2010, 31(9), 2393-2417.

17. Singh, S. K., Applications of hyperspectral data for snowpack characterization in the Himalayan region. $\mathrm{PhD}$ thesis, University, 2013, p. 132.

18. Negi, H. S. and Kokhanovsky, A., Retrieval of snow grain size and albedo of western Himalayan snow cover using satellite data. Cryosphere, 2011, 5, 831-847.

19. Zhao, S., Jiang, T. and Wang, Z., Snow grain-size estimation using Hyperion imagery in a typical area of the Heihe river basin, China. Remote Sensing, 2013, 5, 238-253; doi:10.3390/ rs5010238.

20. Green, R. O., Painter, T. H., Roberts, D. A. and Dozier, J., Measuring the expressed abundance of the three phases of water 
with an imaging spectroradiometer over melting snow. Water Resour. Res., 2006, 42, W10402, 1-12; doi:10.1029/2005WR004509.

21. Painter, T. H., Dozier J., Roberts, D. A., Davis, R. E. and Green, R. O., Retrieval of subpixel snow-covered area and grain size from imaging spectrometer data. Remote Sensing Environ., 2003, 83, 64-77.

22. Painter, T. H., Seidel, F. C., Bryant, A. C., Skiles, S. Mc. and Rittger, K., Imaging spectroscopy of albedo and radiative forcing by light-absorbing impurities in mountain snow. J. Geophys. Res.: Atmos., 2013, 118, 1-13; doi:10.1002/jgrd.50520.

23. Negi, H. S., Chander, S. and Singh, S. K., Snow and glacier investigations using hyperspectral data in the Himalaya. Curr. Sci., 2015, 108(5), 892-902.

24. Slonecker, E. T., Jennings, D. B. and Garofalo, D., Remote sensing of impervious surfaces: a review. Remote Sensing Rev., 2001, 20(3), 227-255.

25. Yuan, F. and Bauer, M. E., Comparison of impervious surface area and normalized difference vegetation index as indicators of surface urban heat island effects in Landsat imagery. Remote Sensing Environ., 2007, 106, 375-386.

26. Weng, Q., Remote sensing of impervious surfaces in the urban areas: requirements, methods, and trends. Remote Sensing Environ., 2012, 117, 34-49.

27. Phinn, S., Stanford, M., Scarth, P., Murray, A. T. and Shyy, P. T., Monitoring the composition of urban environments based on the vegetation-impervious surface-soil (VIS) model by subpixel analysis techniques. Int. J. Remote Sensing, 2002, 23(20), 4131-4153.

28. Deng, C. and Wu, C., A spatially adaptive spectral mixture analysis for mapping subpixel urban impervious surface distribution. Remote Sensing Environ., 2013, 133, 62-70.

29. Sun, G., Chen, X., Ren, J., Zhang, A. and Jia, X., Stratified spectral mixture analysis of medium resolution imagery for impervious surface mapping. Int. J. Appl. Earth Obs. Geoinform., 2017, 60, $38-48$.

30. Small, C., Estimation of urban vegetation abundance by spectral mixture analysis. Int. J. Remote Sensing, 2001, 22(7), 1305-1334.

31. Wu, C. and Murray, A. T., Estimating impervious surface distribution by spectral mixture analysis. Remote Sensing Environ., 2003, 84, 493-505.

32. Yang, J. and He, Y., Automated mapping of impervious surfaces in urban and suburban areas: linear spectral unmixing of high spatial resolution imagery. Int. J. Appl. Earth Observ. Geoinform., 2017, 54, 53-64.

33. Herold, M., Roberts, D. A., Gardner, M. E. and Dennison, P. E., Spectrometry for urban area remote sensing-development and analysis of a spectral library from $350 \mathrm{~nm}$ to $2400 \mathrm{~nm}$. Remote Sensing Environ., 2004, 91, 304-319.

34. Heiden, U., Segl, K., Roessner, S. and Kaufmann, H., Determination of robust spectral features for identification of urban surface materials in hyperspectral remote sensing data. Remote Sensing Environ., 2007, 111, 537-552.

35. Nasarudin, N. E. M. and Shafri, H. Z. M., Development and utilization of urban spectral library for remote sensing of urban environment. J. Urban Environ. Eng., 2011, 5(1), 44-56.

36. Kotthaus, S., Smith, T. E. L., Wooster, M. J. and Grimmond, C. S. B., Derivation of an urban materials spectral library through emittance and reflectance spectroscopy. ISPRS J. Photogramm. Remote Sensing, 2014, 94, 194-212.

37. Weng, Q., Hu, X. and Lu, D., Extracting impervious surface from hyperspectral imagery with linear spectral mixture analysis. In Remote Sensing of Impervious Surfaces (ed. Weng, Q.), Taylor and Francis Group, LLC, Florida, USA, 2008, pp. 93-118.

38. Roessner, S., Segl, K., Heiden, U. and Kaufmann, H., Automated differentiation of urban surfaces based on airborne hyperspectral imagery. IEEE Trans. Geosci. Remote Sensing, 2001, 39(7), 15251532.

39. Herold, M., Gardner, M. E. and Roberts, D. A., Spectral resolution requirements for mapping urban areas. IEEE Trans. Geosci. Remote Sensing, 2003, 41(9), 1907-1919.

40. Sugumaran, R., Gerjevic, J. and Voss, M., Transportation infrastructure extraction using hyperspectral remote sensing. In Remote Sensing of Impervious Surfaces (ed. Weng, Q.), Taylor and Francis Group, LLC, Florida, USA, 2009, pp. 163-178.

41. Franke, J., Roberts, D. A., Halligan, K. and Menz, G., Hierarchical multiple endmember spectral mixture analysis (MESMA) of hyperspectral imagery for urban environments. Remote Sensing Environ., 2009, 113, 1712-1723.

42. Axelsson, M., Friman, O., Haavardsholm, T. V. and Renhorn, I., Target detection in hyperspectral imagery using forward modeling and in-scene information. ISPRS J. Photogramm. Remote Sensing, 2016, 119, 124-134.

43. Chen, F., Wang, K., Voorde, T. V. and Tang, T. F., Mapping urban land cover from high spatial resolution hyperspectral data: an approach based on simultaneously unmixing similar pixels with jointly sparse spectral mixture analysis. Remote Sensing Environ., 2017, 196, 324-342.

44. Chen, F., Jiang, H., Voorde, T. V., Lu, S., Xu, W. and Zhou, Y., Land cover mapping in urban environments using hyperspectral APEX data: a study case in Baden, Switzerland. Int. J. Appl. Earth Observ. Geoinform., 2018, 71, 70-82.

45. Census of India, Primary Census Abstracts, Office of the Registrar General, Government of India, 2011.

46. Flanner, M. G., Zender, C. S., Randerson, J. T. and Rasch, P. J., Present day climate forcing and response from black carbon in snow. J. Geophys. Res., 2007, 112, D11202; doi:10.1029/ 2006JD008003.

47. Flanner, M. G., Zender, C. S., Hess, P. G., Mahowald, N. M., Painter, T. H., Ramanathan, V. and Rasch, P. J., Springtime warming and reduced snow cover from carbonaceous particles. Atmos. Chem. Phys., 2009, 9, 2481-2497.

48. Toon, O. B., McKay, C. P., Ackerman, T. P. and Santhanam, K., Rapid calculation of radiative heating rates and photo dissociation rates in inhomogeneous multiple scattering atmospheres. J. Geophys. Res., 1989, 94(D13), 16287-16301.

49. Bonifazi, G., Capobianco, G. and Serranti, S., Hyperspectral imaging applied to the identification and classification of asbestos fibers. IEEE Sensors, Busan, 2015, pp. 1-4.

50. Gaffey, S. J., Spectral reflectance of carbonate minerals in the visible and near infrared $(0.35-2.55 \mu \mathrm{m})$ : calcite, aragonite, and dolomite. Am. Mineral., 1986, 71, 151-162.

51. Gaffey, S. J., Spectral reflectance of carbonate minerals in the visible and near infrared $(0.35-2.55 \mu \mathrm{m})$ : anhydrous carbonate minerals. J. Geophys. Res., 1987, $92(2), 1429-1440$.

ACKNOWLEDGEMENTS. We thank the Director, Space Applications Centre (SAC, ISRO), Ahmedabad; the Director, Indian Institute of Remote Sensing (ISRO), Dehradun and the Director, Snow and Avalanche Study Establishment (DRDO), Chandigarh for support during this study under AVIRIS-NG airborne campaign programme. Authors express their sincere gratitude to Dr Rajkumar (Deputy Director, EPSA), Dr A. S. Rajawat (Group Director, GHCAG/SAC), Dr B. K. Bhattacharya (SAC) and Robert O. Green (JPL) for initialization and support during the campaign, mode and study. We also thank the SAC and JPL team members for help in collecting AVIRIS-NG dataset over the Himalayan region and urban area of Ahmedabad.

doi: $10.18520 / \mathrm{cs} / \mathrm{v} 116 / \mathrm{i} 7 / 1182-1195$ 